Article

\title{
Beyond the Sit-In: Public Space Production and Appropriation in Sudan's December Revolution, 2018
}

\author{
Ibrahim Z. Bahreldin ${ }^{1,2}$ (D) \\ 1 Department of Urban \& Regional Planning, Faculty of Architecture \& Planning, King Abdulaziz University, \\ Jeddah 22254, Saudi Arabia; iyassein@kau.edu.sa \\ 2 Department of Urban Planning \& Design, Faculty of Architecture, University of Khartoum, \\ Khartoum 321, Sudan
}

Received: 17 April 2020; Accepted: 22 June 2020; Published: 25 June 2020

\begin{abstract}
This article reflects on Khartoum's sit-in space in front of the Army headquarter in Khartoum during Sudan's Nile Spring. The article explores the public discourses, activities, and space transformation during the sit-in, which lasted fifty-eight days. Through studying the sit-in, we aim to discuss how the Nile Spring has, or has not, transformed the conception of what a public space is by examining the functions and activities of the sit-in space as a territory of political exercise. The methodology underlying this research includes direct and participant observation, a follow-up of the sit-in space activities on various media sources, a literature review, and interviews. The conclusions drawn by this article show how the sit-in space has challenged the current relationship between public space and the political ideology by providing a new example of what a public space is. The sit-in space succeeded in revolutionizing the understanding of how public spaces should be imagined, designed, appropriated, and managed. This inquiry has disclosed the necessity to rethink current planning and urban design processes that restrict democratic activities in public spaces.
\end{abstract}

Keywords: reclaiming public space; Sudan revolution 2018; politics of public space; space transformation; the right to the city; the sit-in space; Khartoum

\section{Introduction}

The utilization of public space as a terrain for political discourses and collective contestation has developed into a significant urban trend, engaging popular academic attention [1-5]. This attention has witnessed a novel turn in the last decade, following the Occupy Wall Street movement, the Arab Spring, and the Occupy Gezi Park movement, in Istanbul [6-9]. Such a turn is considered as an opportunity for creating more democratic and social spaces $[4,10,11]$. Several academicians accentuate the significance and importance of democratic political spaces in society $[7,9,10,12-14]$. In addition, the ephemeral use of "occupied" territory and public space has been noted as a critique of the production of the common and an instrument for change $[3,14]$. Therefore, this topic must be scrutinized, inspected, and analyzed in terms of its settings, conditions, norms, and practices.

The topic has previously motivated crucial inquiries into the concepts of the right to the city and the production of space [15,16], the just city [17-19], and the right to revolution [16]. Nonetheless, this article concentrates on the relationship between the occupation of public space as a collective human action and the dynamics of space production and activities, which position the topic in a broader perspective of social, political, and cultural transformation. This article is based on a theoretical but contextual approach, that is substantiated by the conviction that the best method to comprehend a spatial phenomenon and experience is the examination of its process of production [15]. Otherwise stated, space itself does not have a peculiar meaning: its numerous meanings and values are dictated 
by the set of activities generated by the different groups of inhabitants who are involved in its planning, appropriation, utilization, development, and management [1].

Indeed, the occupation of urban spaces directly contests the power structure by challenging the power, functions, and symbolisms that produced that space $[7,15,20]$. Hence, the employment of the occupied space and its production and appropriation cannot be detached from the process of production and consumption of space with its multilayered dimensions, including the political, social, economic, and cultural [15].

The paper focuses on the sit-in space that was constructed during Sudan's December 2018 revolution, as a unique form of public space occupation and appropriation. The deliberation on the roots and the impacts of the December uprising in Sudan and the occupied sit-in space on public space production, appropriation, and consumption continues to occupy scholars [4,21]. The unfolding of events in April and May of 2019 in the al-Qeyada sit-in space in Khartoum-the place where protestors deliberated, designed, and created their temporal city-is a fertile field for researchers and scientists. Indeed, the sit-in space and the protests that led to overthrowing al-Bashir regime were not merely the latest installments of a series of movements of resistance against the authoritarian rule. The occupation of public space as a tool of political activism witnessed a new turn in Sudan after April 2019. The consequences of Khartoum's sit-in events are likely to mark a juncture where space production and appropriation strategies and methods instigate a new frontier of research among scholars and activists.

The history of public discourses in Sudan documented that the previous two Sudanese revolutions took place in the public space. The first Sudanese revolution, in 1964, was strongly represented in Midan al-Shuhada, in front of the Republic Palace, in Khartoum's downtown [22]. April Intifada's revolution of 1985, however, unfolded in both Abu-Ginzeer Square and al-Gasr Park (previously Midan al-Shuhada) [23]. Despite the lack of relevant literature, the politics of public space seems to be strongly associated with Sudan's modern history. Many public spaces in Khartoum are well known for their political images, as they have exhibited or continued to show political messages and expectations. Examples include Midan Agrab, in Khartoum North city; United Nations Square; Midan al-Shuhada, in Omdurman; Six of April Park; Abu-Ginzeer Square, in Khartoum; and Midan Burry, in eastern Khartoum.

However, since the al-Bashir military coup in 1989, public space in Khartoum has been unceasingly privatized [24], neglected [25,26], and segregated [27]. This process is visible in open spaces, riverfronts, rural landscapes, urban green areas, parks, squares, and even streets. Spaces like the International Park in Khartoum; Khartoum and Omdurman riverfronts; al-Mogran family Park; Six of April Park; the National Zoo; the Family Park; and United Nations square, in Khartoum, have entirely or partially lost their civic title and were progressively privatized, segregated or controlled. The control over the public realm practiced by the previous regime extended beyond the public space to private open spaces. Spaces like the Atanei coffee shop Square, in Khartoum's downtown, which hosted the famous Mfroosh social and cultural event. The controversial nature of its political activities eventually led to its closure.

The aforementioned examples show that public spaces during the last regime were either places for passage [24] or to show off state dominance and control [25]. Consequently, those spaces were designed fearfully or marginally, in a way that has triggered a struggle between architecture, the local people, and the state [22]. Under these circumstances, the Nile spring in Sudan has challenged several of the political, social, and economic forces that have shaped-and continue to shape-the public realm, the public sphere, and the public domain. It is in this context that any "right to Khartoum city" must be developed. The contest to reclaim this right was demonstrated in the sit-in space occupation and the events that followed.

\section{The Revolution, Democracy and Public Space}

A cursory reading of the scholarly work on the production of space, place-making, and democracy demonstrates how these three fundamental urban terms were often espoused. The point of departure and intellectual inspiration for the production of space, as well as much current work on the right 
to the city, commences with the work of Henri Lefebvre. In his seminal work, "The Production of Space", Lefebvre studied struggles over the meaning of space. He reflected on how relations across terrains were given cultural meaning through a three-dimensional dialectic on the production of space as related to the "right to the city". Lefebvre identified the spatialities of social existence and the ways in which those spatialities are produced, lived, and experienced [15]. In his theory, Lefebvre indicated that the production of space could be divided analytically into three dialectically interrelated dimensions or processes. These dimensions, or "formants", are (1) the representations of space, (2) the representational space, and (3) the spatial practices [15].

Representations of space or the "conceived space" try to command social relations. These spaces are produced by city planners, real estate developers, technocrats, and bureaucrats. Hence, those spaces are "tied to the relations of production and to the 'order' which those relations impose, and hence to knowledge, to signs, to codes" [15] (p. 33). Representations of space tell the inhabitants what to do-or not to do, what is allowed-and what is not allowed in a certain space. Those spaces are influenced by knowledge and ideology. Representational spaces or the "lived space", however, are those spaces produced by inhabitants via their daily use. Such spaces are directly lived in everyday life. Lefebvre described those spaces as "linked to the clandestine or underground side of social life, as also to art" [15] (p. 33). Spatial practice or the "perceived space" refers to the production and reproduction of a particular social formation, such as capitalism [15] (p. 33).

Lefebvre's spatial triad elucidates the struggle over the production of space in the urban context. In this regard, he differentiates between what he calls the "industrial city" and "urban society" [28]. For Lefebvre, the industrial city is the city that is profoundly shaped by private property and exchange value. In such a city, the dominant social and spatial practices segregate inhabitants [28]. The urban inhabitants in the industrial city are politically inactive, and they behave as consumers rather than citizens [29]. In contrast, in urban society, urban space is governed by inhabitants who appropriate space and utilize it to achieve their needs. In urban society, inhabitants are at the center of space, in which they engage in cooperative and meaningful negotiations about the city they want $[28,29]$.

Comparable arguments have been deployed in reference to the right to the city and the urban revolution in Harvey [16]. Stimulated by the modern waves of urban struggles, Harvey [16] cross-examines the right to the city in which he defines as "... not merely a right of access to what exists, but a right to change it after our heart's desire. We need to be sure we can live with our own creations ... But the right to remake ourselves by creating a qualitatively different kind of urban sociality is one of the most precious of all human rights" [16] (p. 236). In his investigation, Harvey [16] argues that "The urban obviously functions, then, as an important site of political action and revolt. The actual site characteristics are important, and the physical and social re-engineering and territorial organization of these sites is a weapon in political struggle". For Harvey, cities have been radically transformed in the interests of capital, which resulted in less democratic spaces [16] (p. 118). Building on Lefebvre's essay on the right to the city, Harvey [16] calls for radically democratic cities and more equitable, playful, and meaningful spaces. Harvey also warns that in the absence of the right to the city, cities will offer alternatives to neo-liberalism in local settings. Therefore, cities will tremble under waves of discontent exercising their right to the city, which he defines as claiming "... some kind of shaping power over the processes of urbanization, over the ways in which our cities are made and remade, and to do so in a fundamental and radical way". Harvey [16], considers urban revolution-notably Occupy Wall Street-as an endeavor to transform public space into a political common, and this common must be collective and non-commodified, like Habermas's public sphere [30].

Several other investigations have attempted to provide a different perspective on how to connect urban design, revolution, and public spaces. More precisely, how to dictate the bond between people and space, as well as how to measure the quality of an occupied space. We recall four compelling concepts that highlight this notion in imperative ways. For instance, Gottdiener \& Hutchison [31] highlight that though economic, political, and social institutions create, and recreate, urban space, the meaning of these spaces is generated by local inhabitants. Otherwise stated, space is not merely a 
container of people and activities; urban space both creates specific patterns of social relations and is continually changed and recreated by the social networks that take place there. Such creation is quite similar to Lefebvre's [15] "conceived" and "lived space". Although Gottdiener \& Hutchison [31] have provided a general conception of how to measure the quality of the occupied space, utilizing place meaning and activities, they did not provide a criterion of success to benchmark the meaning of the occupied space.

Scannell \& Gifford [32] presented an exciting tripartite model of the relationship between people and places. Their framework proposes that place attachment is a multidimensional concept involving a person, a psychological process, and place dimensions. The first dimension of Scannell \& Gifford's [32] model is the actor; this entails the following questions: Who is attached? To what extent is the attachment based on individually and collectively held meanings? The second dimension is the psychological process: How are affect, cognition, and behavior manifested in the attachment? The third dimension is the object of the attachment, including place characteristics: What is the attachment to, and what is the nature of, this place? [32]. Scannell \& Gifford's framework has explained some of the complexities found in Gottdiener \& Hutchison's [31] perception of the quality—or the meaning —of the public space. In other words, Scannell \& Gifford make it clear that we can measure the quality of public spaces—at least in principle-by asking: (1) Who are the actors? (2) How is the behavior manifested in space (the activities)?, and (3) What is the nature of the place (the physical setting)?

Looking at public space through the prism of planning, Carmona [33] proposes a set of ten rules that make public space successful. These rules, which describe the character of space are: (1) Evolving (whether formal or informal in nature); (2) Diverse (avoiding one-size-fits-all); (3) Free (with secure rights and responsibilities); (4) Delineated (clearly public in their use); (5) Engaging (designing of active uses); (6) Meaningful (incorporating notable amenities and features); (7) Social (encouraging social engagement); (8) Balanced (between traffic and pedestrians); (9) Comfortable; and (10) Robust (adaptable and distinct in the face of change). In the same regard, the Project for Public Space (PPS) claimed that "a successful public space generally needs to offer four qualities: it should be accessible, it should be comfortable and have a good image, people should be able to engage in an array of activities, and, it should be sociable" [34].

Both Carmona [33] and the Project for Public Space [34] emphasized the importance not only of the activities in public spaces but also of how these activities transform into a collective social construct. In other words, they both highlighted the importance of the social and physical settings while measuring the space quality. Interestingly, some of these criteria fit nicely with Lefebvre's [15] and Harvey's [16] definition of the right to the city, as well as with Lefebvre's [15] spatial triad. Notably, the way in which the quality of space is attached to the process of its production-whether it is a perceived or a conceived space. In addition, the scholarly work exhibited above emphasized the importance of collective action, diversity, and meaning while shaping or reshaping those spaces.

The narrative presented above exemplifies that the struggle over the urban spaces as a spatial phenomenon is uncontested $[15,16]$. The consequences of such a struggle can lead to citizens' discontent and dissatisfaction. Therefore, citizens may exercise their "right to the city" through various forms, including space occupation. The production of space-including the spaces produced during the revolution, like Khartoum's sit-in—cannot be comprehended without studying its meaning, value, and activities. In this regard, the best method to understand a spatial phenomenon and experience would be to examine its process of production [15]. Otherwise stated, space does not have a specific significance or meaning: it dictates its meaning through the activities performed by the different groups of inhabitants through their engagement in the process of space appropriation and re-appropriation. In addition, the meaning and the quality of these spaces are generated by both getting the people into space itself [35] and benchmarking them against the rules for successful public spaces-such as those of Carmona [33] and the PPS [34]. Similarly, the "lived space" as deliberated by Lefebvre [15], paired with the place attachment framework in Scannell \& Gifford's [32] work, exhibits a people-centered approach 
to understand the meaning of urban space. These approaches provide a great example for recognizing the typologies, structure, and activities of political space, including Khartoum's sit-in.

\section{Aims, Objectives, and Methods}

This article reflects on Khartoum's sit-in space during the Nile Spring, exploring the public discourses, activities, and the space transformation during the sit-in period in April-May 2019. The spatialities we are trying to explain in this article are the source of several complexities in understanding revolution, public space, and politics. Hence, this article is based on a proposition of the philosopher Henri Lefebvre and his major philosophical work, "The Production of Space", in which he interrogates whether it is " ... conceivable that the exercise of hegemony might leave space untouched?" [15]. The article is a modest attempt to react to this question, presenting the Nile Spring and the sit-in space as an example.

Through the study of the sit-in space, we aim to exhibit how the Nile Spring has, or has not, transformed the very conception of what a public space is by examining the functions of the sit-in space as a territory of political exercise. It must be noted that the analysis in this paper is grounded in four methods, including:

1. Direct and participant observation.

2. Follow-up of the sit-in space activities on various media sources, social networking sites, and digital newspapers.

3. Literature reviewing.

4. Interviews with activists, scholars, journalists, and politicians.

The observation was carried out to document both the activities and the nature of the spatial constructs erected in the sit-in space. This includes temporal constructs such as barricades, services, and infrastructure. Throughout our observation of the sit-in, we utilized three observation sampling methods, including events sampling, time sampling, and spatial sampling. For event sampling, we decided to focus on activities that involve more than five people at the moment of action. This number excludes activities that, by their nature, require two or fewer people, such as dating and commercial activities. For time sampling, the observation was carried out three times a day-in the morning, in the afternoon, and in the evening-for at least $60 \mathrm{~min}$ for each interval. The observation itself was carried out randomly for five consecutive days. The spatial sampling, however, was done by dividing the sit-in space into three spatial zones-the eastern zone, the central zone, and the western zone. Such division was necessary considering the remarkably large sit-in area, which measured around 27.5 hectares.

The observation sheet documents five primary constructs: the nature of the activity (temporal, active, passive); the location of the activity; who is involved in the activity (age group, gender); the goal of the activity; and the rules that govern the activity and behavior. Due to the limitations imposed by the observation technique - namely, the limited scope of the observation (five days) - the utilization of the participant observation methodology was supported by follow-ups of the sit-in daily activities as documented by the mass media and social groups. We reviewed seven documentaries and media reports about the sit-in and followed the daily post of the journalists, activists, and, most importantly, the sit-in Media Group on Facebook, Twitter, and Instagram.

A literature review was also conducted to support the theoretical and contextual aspects of the research. While the literature reviewed provided a reasonable theoretical structure, it was difficult to contextualize the research due to the lack of relevant literature on public space in Khartoum. We tried to curtail such a knowledge gap by utilizing interviews as an alternative methodology.

The interviews in this research were explored for two main purposes; to fill in the knowledge gaps about the literature on public spaces and activism in Khartoum and to support or negate the outcomes of the observation-based analysis. We utilized semi-structured interviews, which were mostly done in person and by telephone. The utilization of semi-structured interviews was justified by 
the lack of research on the topic. Respondents were divided into two groups. The first group included two university professors and a historian. The questions highlighted for this group concentrated on the relationship between the revolution, democracy, and the public space in Khartoum. The second group included four activists, two journalists, and two politicians. The questions raised for this group included inquiries about the nature and the role of both the activities and the spatial constructs in the sit-in. The members of this group were also requested to reflect on their experience and how they envisioned the sit-in compared to other spaces in Khartoum.

\section{Sudan's Third Revolution (2018) and Khartoum's Sit-In Space}

Throughout the three decades of al-Bashir's dictatorship, Khartoum was progressively transformed into a fortress that exhibited the power and ideology of the governing regime [25]. Public spaces were privatized [24], municipal building displayed the power of the Islamist rulers [25], and access to the free public sphere was controlled [36]. However, spaces designed to provide the setting for showing off the architectural magnificence and the power of a government often become the very place where the public assembles to protest directly against that regime. The occupation of urban spaces directly contests the power structure by challenging the functions and symbolisms of those spaces. The sit-in space that was constructed during Sudan's December 2018 revolution is a true manifestation of this.

The public movement against al-Bashir's government began as early as 2018. However, it gained momentum in late 2018, when the demonstrations commenced in the city of al-Damazin. Since then, a series of protests broke out throughout the country due to the rising costs of living and the deterioration of socio-economic conditions. The most notable event that led to the success of revolution was when the protestors decided to occupy the space in front of the al-Qeyada (the Army headquarters), in Khartoum, forming the first mass sit-in in the country's modern history (Figures 1 and 2). The sit-in, which lasted for fifty-eight days before it was dispersed, fueled a series of events that led the Sudanese Army to arrest al-Bashir and take control of the government.

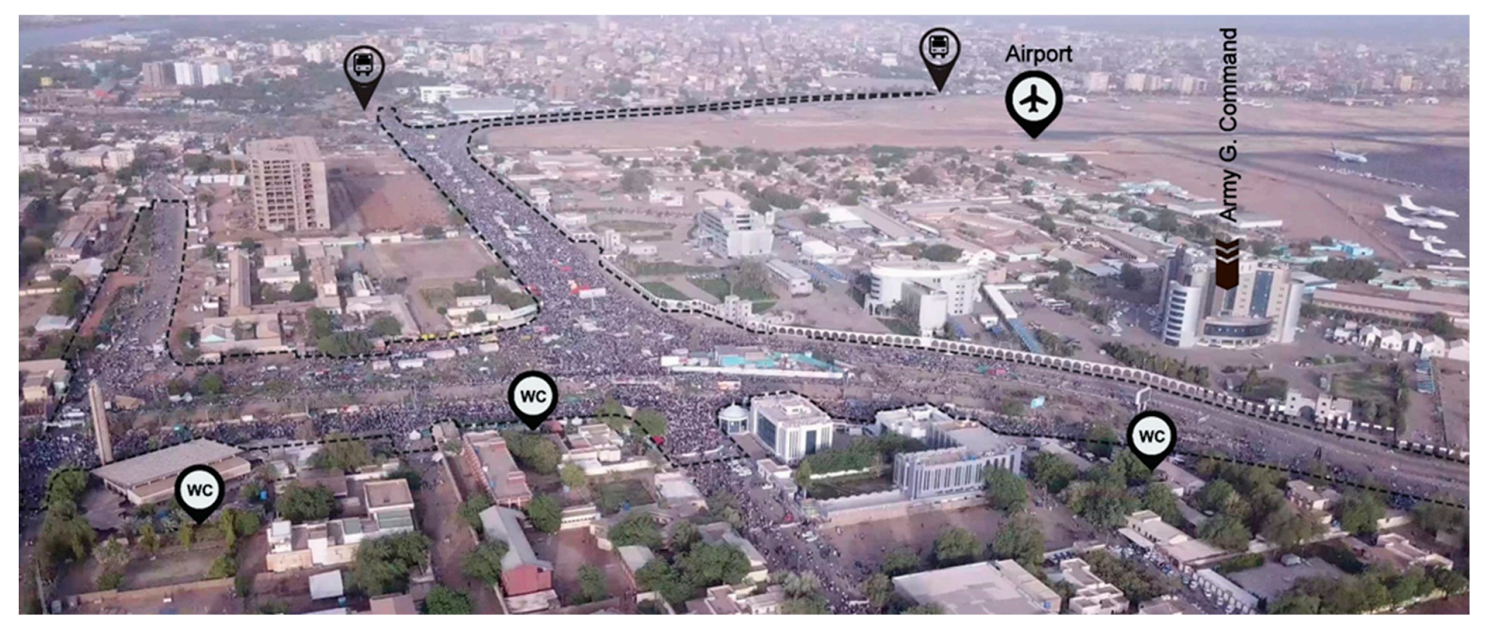

Figure 1. A drone image shows the crowds of protestors as they assemble at the sit-in space in front of al-Qeyada on 18 April 2019. The black dotted line shows the limits of the sit-in space. Photo courtesy of Waddah Hago.

The occupied sit-in space is located at the geographic center of Greater Khartoum, adjacent to Khartoum's center from the east (Figure 3). Many of the major streets in Khartoum, such as Obeid Khatim Street and al-Imam al-Mahadi Street, pass right at the edges of the space, from the east and the west, respectively. The Nile Avenue is just a couple of minutes' walk north of the sit-in. The entire occupied spaces have five main entry points, two from the east and three from the west. The total area of the sit-in space was estimated at 108 hectares (see Figure 4). This area comprises many administrative services and educational facilities. However, the active site of the sit-in space, where most of the 
activities took place, was calculated to be around 27.5 hectares. It should be noted that the sit-in space has a dynamic nature. Protestors expanded the space and retracted it according to their requirements.

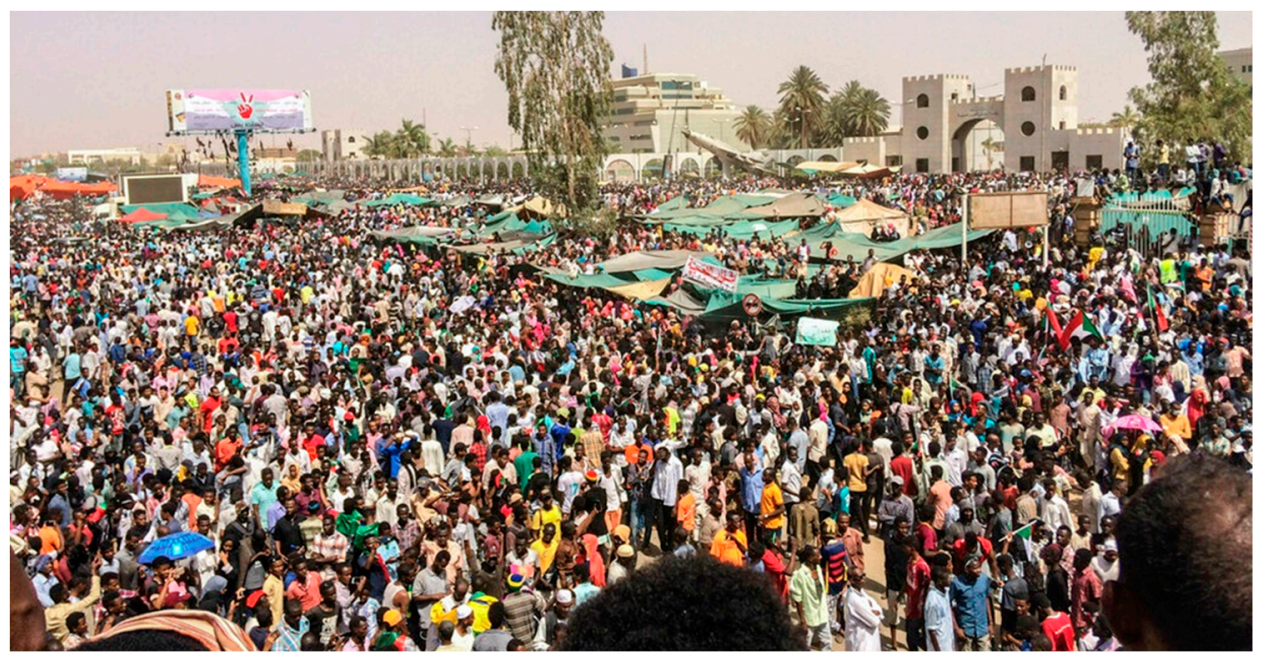

Figure 2. Photo of the protestors as they assembled in the sit-in in front of the Army headquarters in April 2019. Photo courtesy of Ali Gaffar.

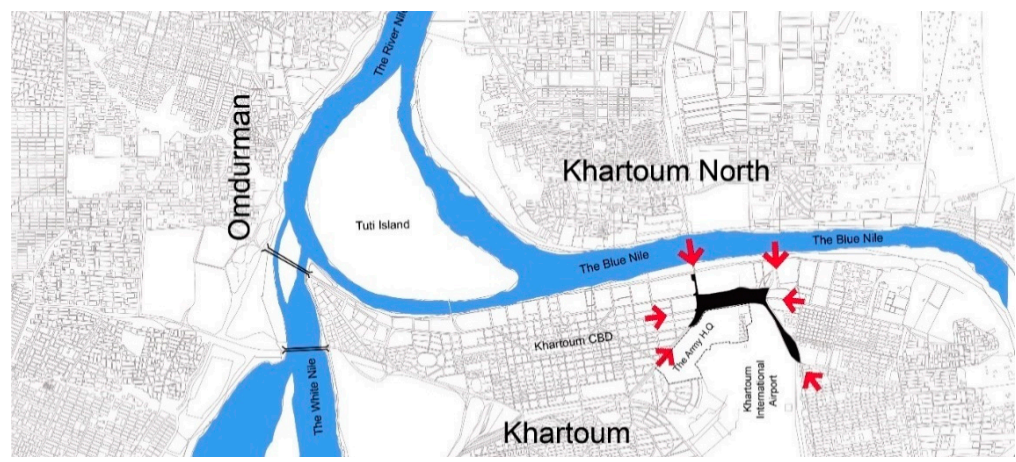

Figure 3. Location of the sit-in space in Khartoum (marked in black). The red arrows show the major access points to the sit-in.

The area of al-Qeyada is accessible from 15 streets, some of which extend for kilometers into the urban structure of the city. The eastern boundary of the sit-in space is the Peace Park, "Hadaegg as-Salam". This park is directly bordering a crossing of three primary street connections heading to Khartoum North city across the Blue Nile, to eastern Khartoum and Burri, and to southern Khartoum through Obeid Khatim street. The western boundary of the sit-in space is enclosed by al-Imam al-Mahadi Street, which also leads to northern Khartoum through the famous Blue Nile Bridge. The University of Khartoum's main campus, the University of Khartoum's mosque, the Bankers Union, and the College of Medical and Radiologic Sciences also adjoin this side of the sit-in space. The Army headquarters demarcates the sit-in space on the south (Figure 4). Several colonial buildings border the revolt spaces, including the students' hostels and Khartoum University Hospital, to the north (the British Barracks before the country's independence).

While the urban design context of al-Qeyada does not make the sit-in space the perfect place to launch a revolution (Figure 5), the imperative of location and the excellent accessibility makes the sit-in space one of the most appropriate meeting points for protestors. Moreover, its symbolic meaning may have brought other factors into play. The sit-in space is surrounded by three main points that demonstrate the regime's power and control. First and foremost, the Army headquarters; second, the University of Khartoum's mosque, to the west, which is a hallmark of the regime's Islamist students' activities within the University of Khartoum and other universities in the city; third, the Police Officers' 
Club to the east of the sit-in space. These three spatial components might have qualified the sit-in space as a genuine contestation against the power of the regime.

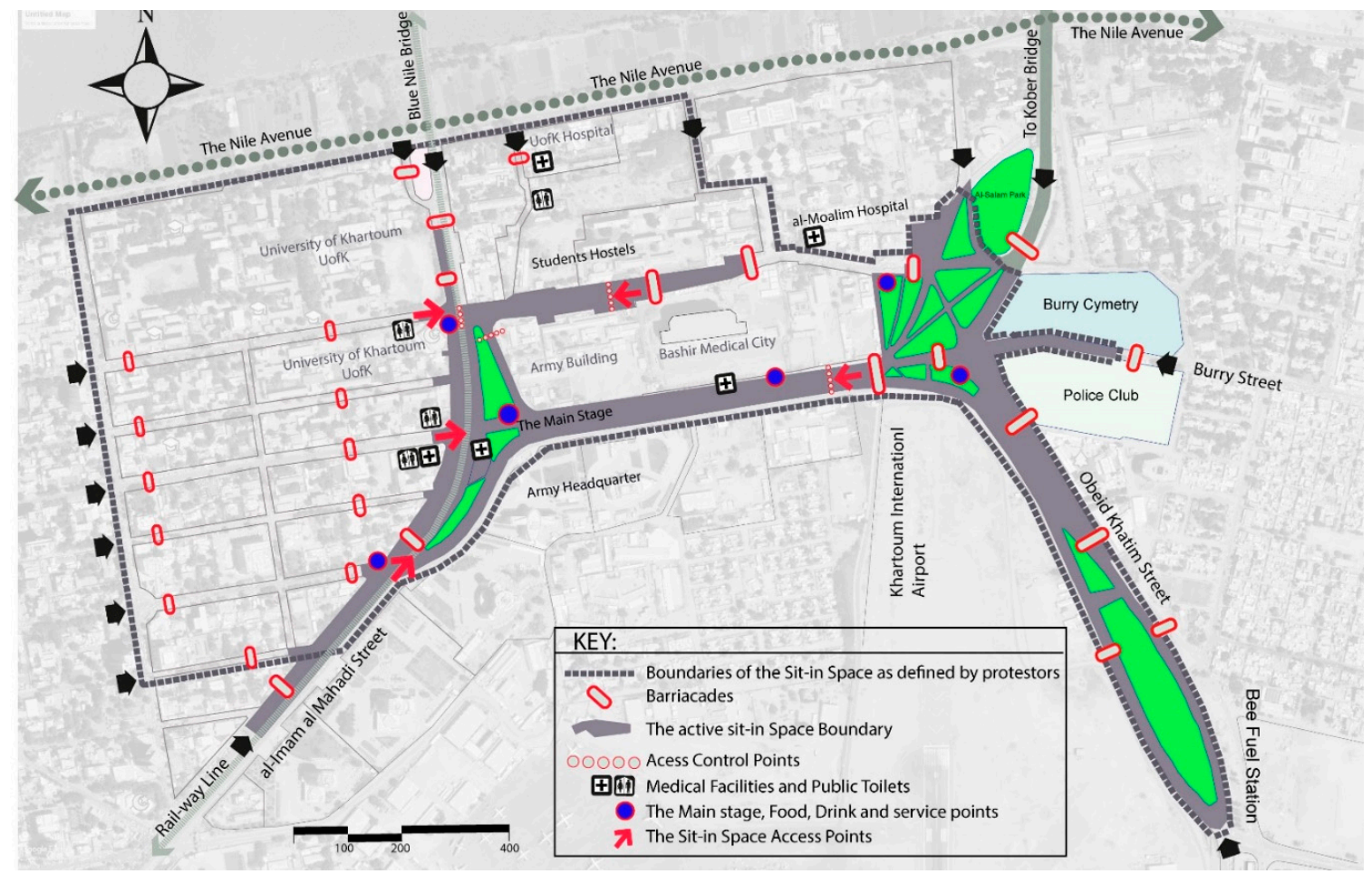

Figure 4. The sit-in space as of 29 May 2019. This map shows the major spatial constructs, including barricades, control points, the main stage, and service points.

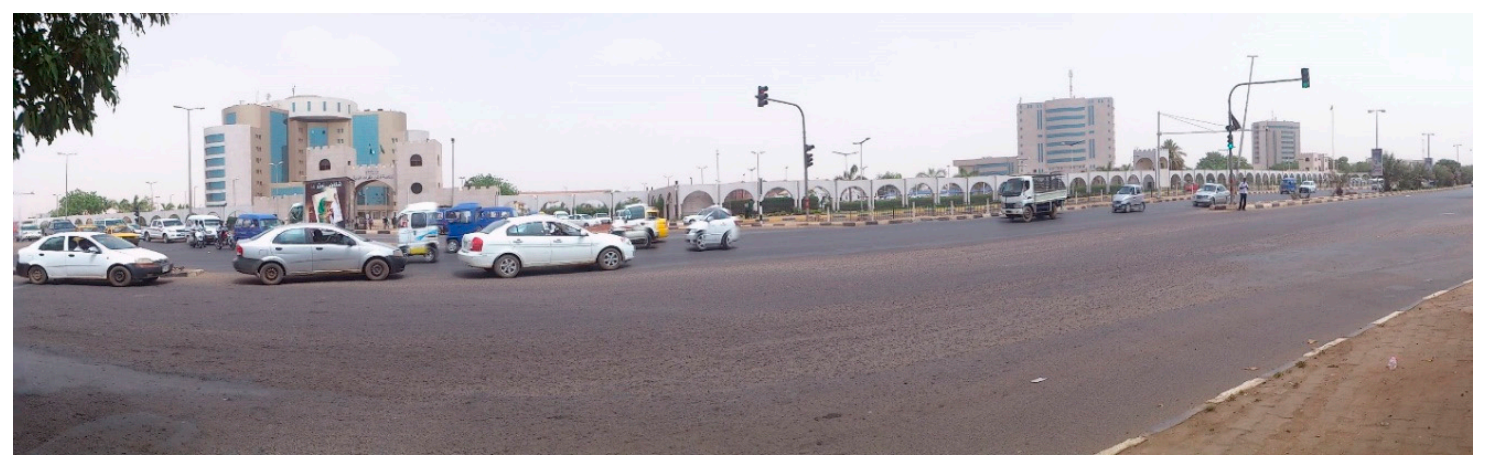

Figure 5. Panoramic view of the western side of the al-Qeyada area in 2018, showing how the site was dominated by car traffic before the sit-in.

\section{The Founding of an Ephemeral, Free City}

The sit-in was a center of multiple events, activities, and debates during Sudan's third revolution. Once the protestors occupied the sit-in space on the six of April 2019, they started securing entrances, setting up encampments, hoisting their banners, and chanting their slogans demanding the departure of the "corrupt" government. Early revolutionists have resided in the median spaces facing the Navi entrance (Figure 6), turning it into a camping area while using the surrounding streets as rallies, marching spaces, and spaces for political, social, and cultural debates. Three days after the occupation of the sit-in, it became a symbol of the public space, the public sphere, the public domain that never was. Based on our five days of observations and interviews, several spatial and temporal constructs were observed in the sit-in space, three of which played a significant role in the sit-in's functionality. Those constructs were: 
1. The variety of activities found in the sit-in.

2. The barricades surrounding the sit-in space.

3. The public arts, graffiti, and culture produced and consumed in the sit-in space.

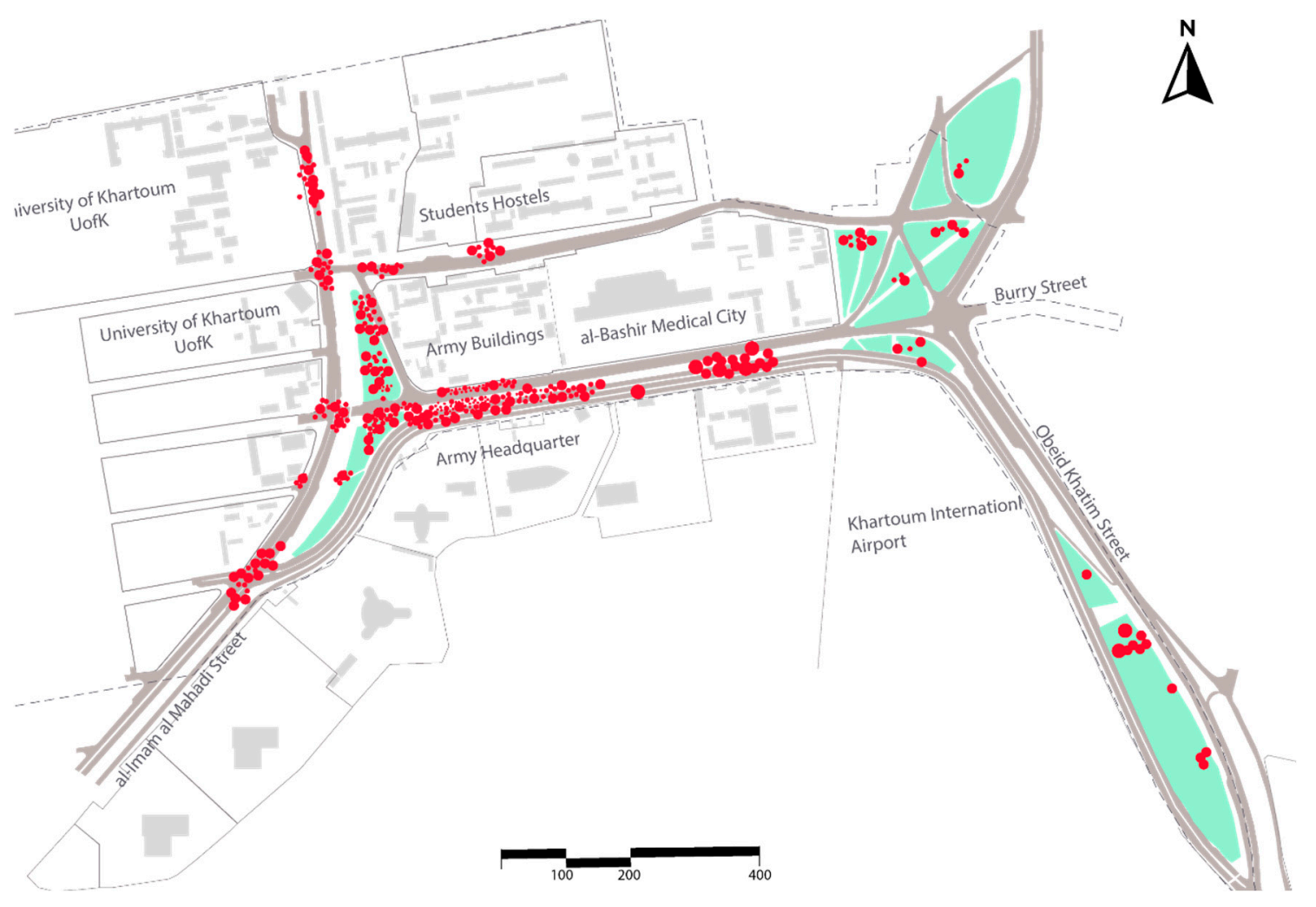

Figure 6. A map showing the general settings of the sit-in and the areas where most protestors were assembling as of 18 May 2019.

\subsection{The Sit-In Space's Activities and Functions}

The sit-in space's activities and functions have certainly contributed to the success of the sit-in space as a territory of political, social, and cultural contestation. In this regard, the sit-in space's assortment of activities was very wide. We managed to document forty-six different activities that were happening in the sit-in space throughout our five days of observation. Based on their nature, those activities were grouped into eleven main activity themes, as follows; (1) Political activities; (2) Social activities; (3) Cultural activities; (4) Artistic activities; (5) Cheering activities; (6) Sport and leisure activities; (7) Religious activities; (8) Safety and security activities; (9) Media and information activities; (10) Economic activities; and (11) Service and infrastructure activities. We further clustered these eleven activity groups into three domains of events/activities that indicate their nature, temporality, location, and magnitude. Those domains are explained hereafter.

The first is the "main" activities domain, which we describe as that of the activities that have been comprehensively practiced at the sit-in space regardless of location, time, and space. These activities happened in a spontaneous or organized way, but they tended to include large groups of protestors. These activities were observed all over the sit-in space's active inner area, with a tendency to concentrate around the central area of the sit-in, where the main stage was located (see Figure 7). The activities in this domain fostered the generation of a democratic, creative, social, and cultural public realm. Most of the activities practiced in this domain (shown in Figures 7 and 8) have lasted throughout the fifty-eight days of the sit-in space. The activities that qualified to fit in this domain were the political, social, cultural, and economic activities. 


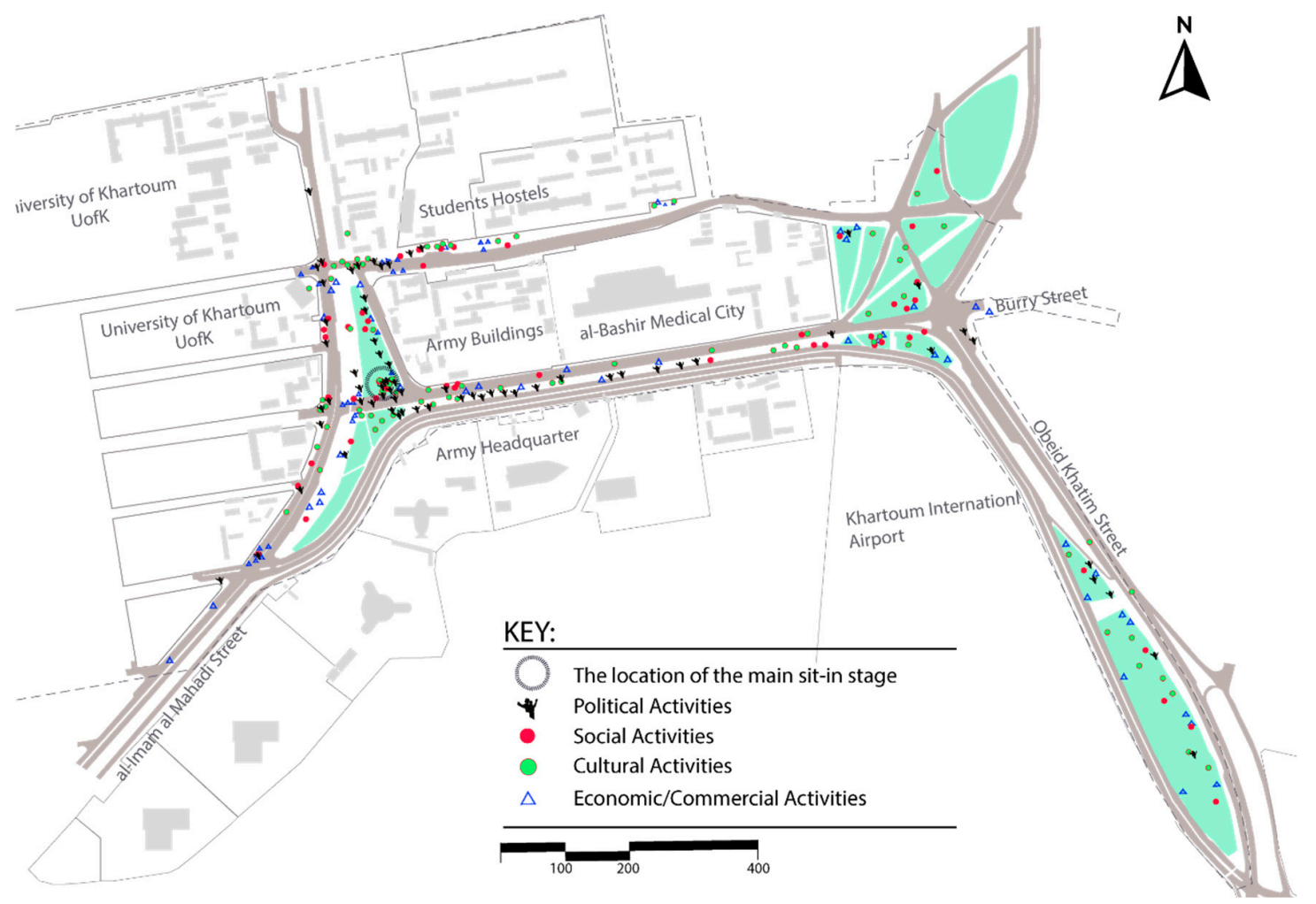

Figure 7. The locations of the major activities as documented in Khartoum's sit-in space.

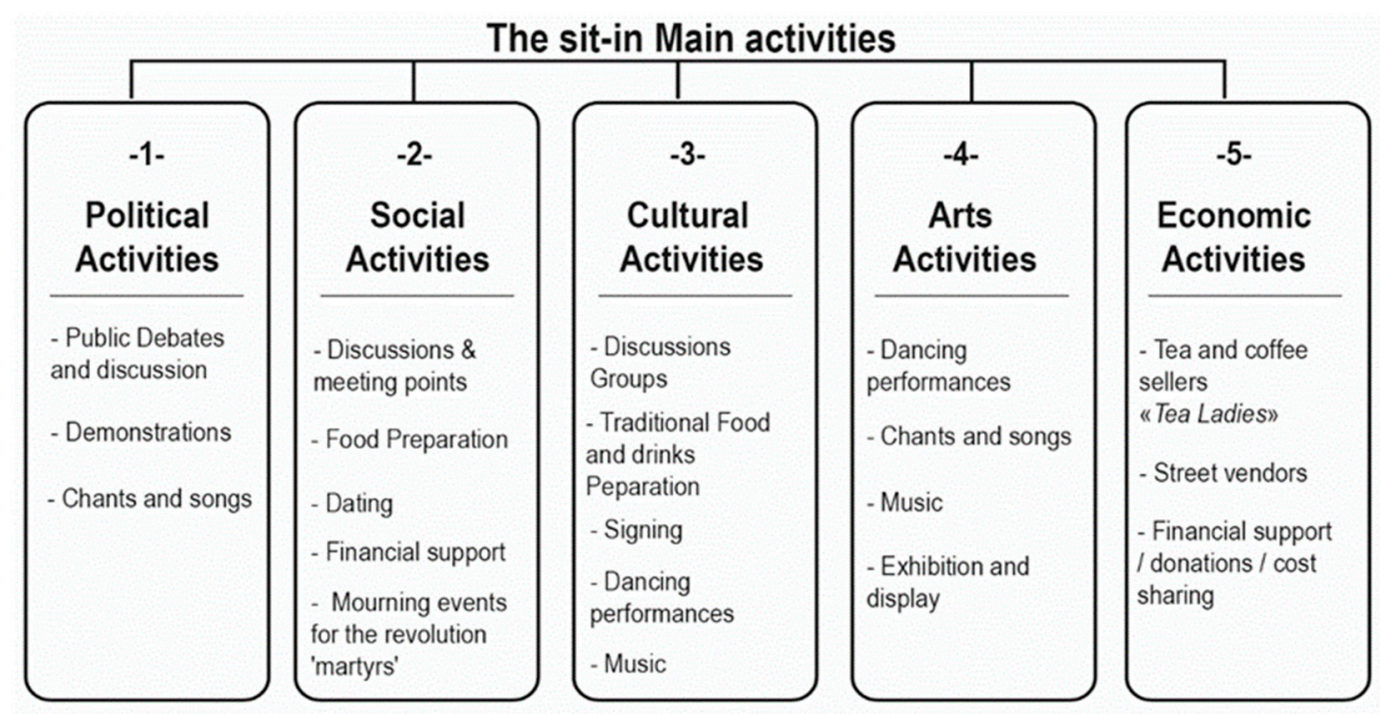

Figure 8. The sit-in's "main" activities domain.

The second domain of activities in the sit-in is the "service" domain. This domain includes most of the functions that support the "main" activities in a way that would improve the quality and the quantity of those activities. Although the majority of the activities in this domain were based on voluntary work, they are characterized as being well organized, having a specific spatial location, and involving clear responsibilities assumed mostly by defined volunteer protestors [37]. The assortment of activities observed in this domain (shown in Figure 9) ranged from activities that were initiated as early as the sit-in occupation, i.e., barricading the sit-in and the encampment, to activities that were only introduced after the protestors assumed control of the sit-in space, i.e., sit-in radio and public announcement systems, electricity supply, cooking areas, drinking water stations (Figure 10), toilets, praying spaces, performance stages, Wifi hotspots, the lighting of the sit-in as well 
as a lost and found space "tent". Many professionally trained protestors, including engineers, medical doctors, pharmacists, artists, journalists, chefs, religious leaders, educators, and even former police officers volunteered to set up and maintain those services/activities. The activities that belong to this domain are what made many professional protestors passionately engage with the sit-in space activities, due to their feeling of responsibility toward providing these services to their fellow protestors [37].

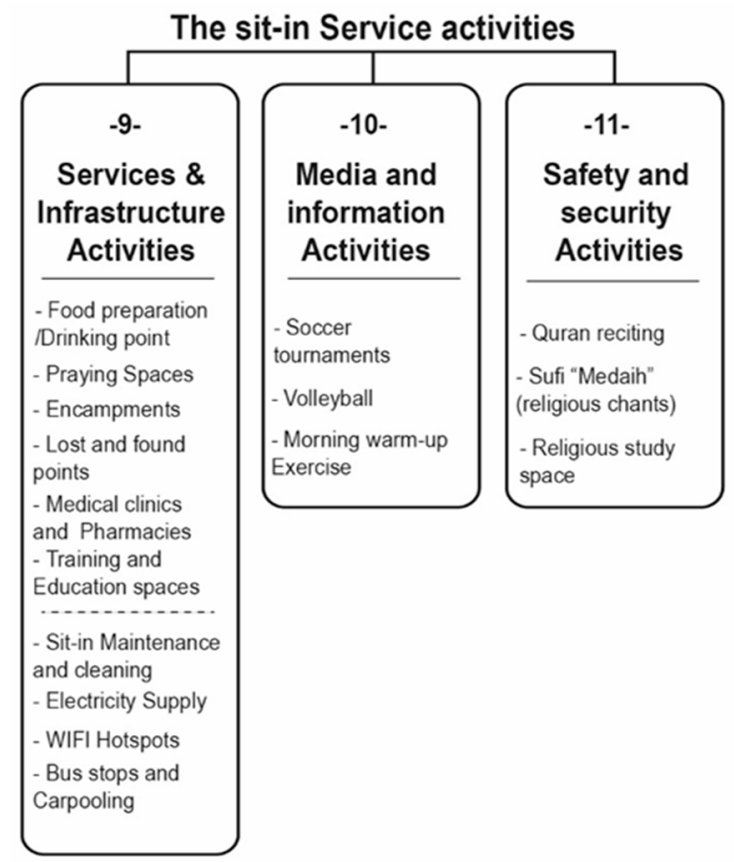

Figure 9. The sit-in "service" activities domain.

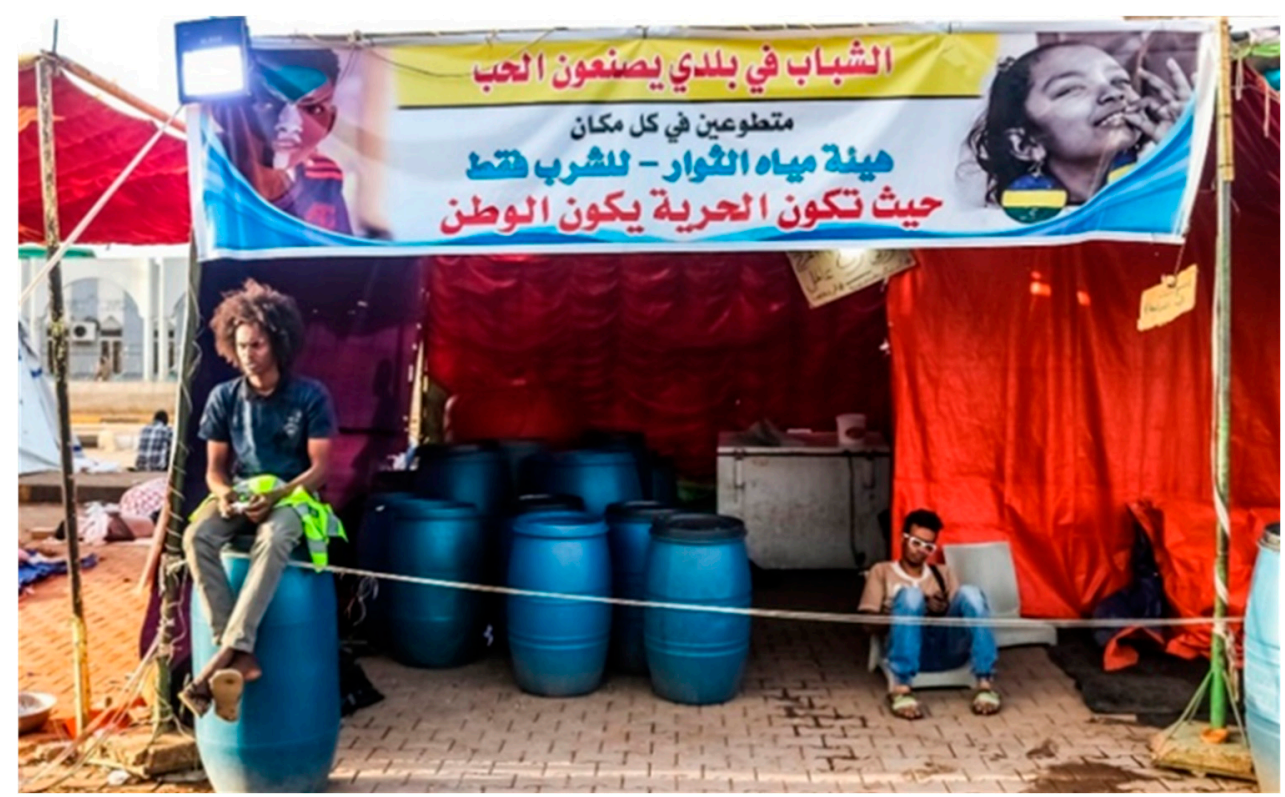

Figure 10. A drinking water station at the sit-in space with a banner saying, "where there is freedom, there is a homeland". Image courtesy of Ali Gaffar.

The third domain is the "supportive or optional" activities domain (see Figure 11). The activities in this domain did not involve many protestors, but they helped improve the quality of the sit-in space significantly. Examples include the sports tournaments, religious activities-notably during the holy month of Ramadan (Figure 12) —and the special music parades and dancing/singing performances. 
The sit-in Supportive/ Optional activities

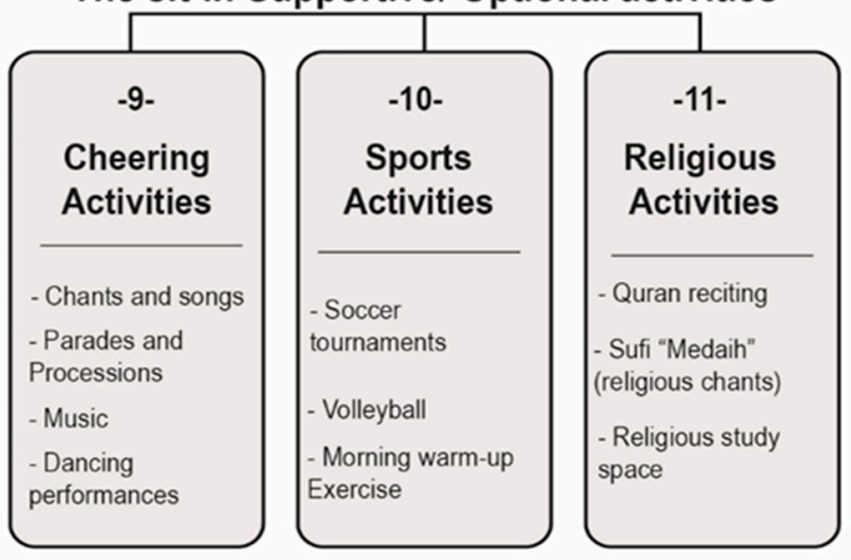

Figure 11. The sit-in "supportive/optional" activities domain.

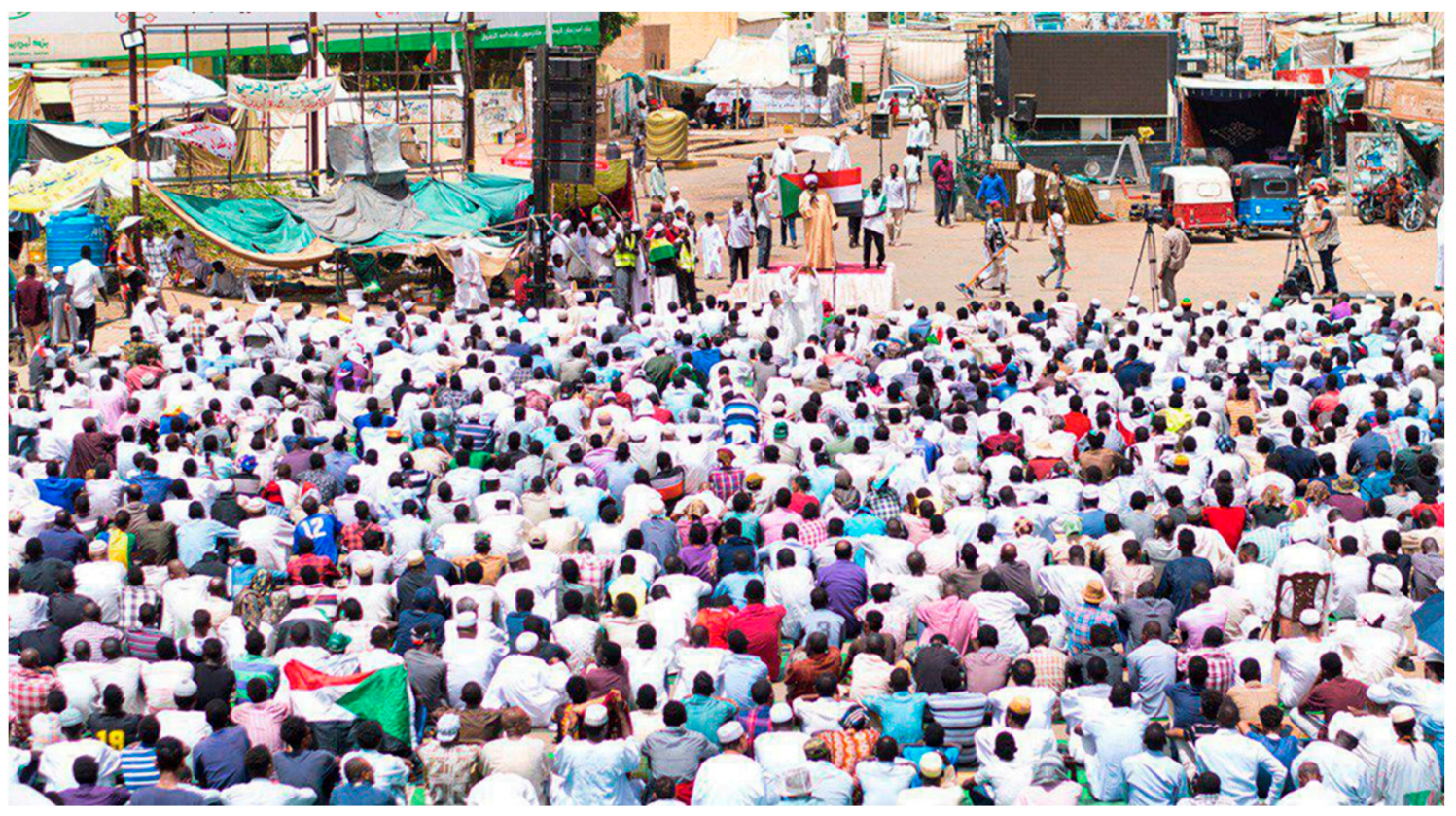

Figure 12. A photo that shows the protestors while performing prayers in the sit-in during the holy month of Ramadan. Image courtesy of the Sit-in Media Group.

The above-mentioned three domains of activities have transformed al-Qeyada area from a couple of parallel streets to "a city within a city or a country in a city" [38]. The sit-in space was gradually transformed into a place where protestors lived, learned, danced, sang, chanted, guarded the access points and barricades, shared ideas, made and consume art and music, watched movies and films, and attended concerts and exhibitions. al-Qeyada was also converted into a place where protestors prepared food and drinks, slept, prayed, read books and newspapers, studied and recited the Quran, discussed, debated, accessed health services and medication, cleaned and maintained the space, socialized, demonstrated, volunteered, and, most prominently, practiced their freedom of speech and expression. It practically became the protestors' home, their front yard and living room, and a prism through which they saw and understood the revolution. The spectrum of activities listed above only delivers a general overview. Many events fit into one or more of the groups listed above. Protestors were ground-breaking in mixing those activities with the dominant activity observed in the sit-in (the political activity).

The construction of the public stage on the Western side of the sit-in (Figures 4 and 7) has enormously boosted the sit-in's activities. This stage acted as the main activity domain for the 
sit-in. However, the scorching hot weather of Khartoum in April has made the whole sit-in and this stage the center of most of the night, early morning, and late afternoon activities. It was also the theater of cultures, arts, information, and political debates, in which most of the music concerts, dancing performances, critical political debates, and media press releases were organized. Besides, it played a crucial landmark function through which the sit-in legibility was understood [37]. It is not surprising, therefore, that the stage was one of the first items to be burned after the sit-in dispersed on the third of June, 2019.

Additionally, the sit-in space encompassed various community groups. In this regard, women's role in boosting the sit-in activities was remarkably unchallenged. Women's condition during the al-Bashir regime was unorthodox. Through "public order" laws, the government excluded women from public space. For three decades, women in Sudan have fought against this oppression. So, it was no surprise that they were out in significant numbers during the December revolution and in the sit-in [27]. Women from all sections of society, whether students, academics, housewives, unemployed, and street traders have participated in several aspects of the Nile Spring and the sit-in activities. They demonstrated, took over the streets, built and protected the barricades, initiated the demonstration, participated in the sit-in and the sit-in events, and prepared food and drinks for the protestors in the sit-in space.

\subsection{The Sit-In Makeshift Barricades}

The second important construct were the barricades surrounding the sit-in space. They served both a practical and symbolic meaning. From the practical perspective, the barricades were defensive, offensive, and management instruments of the revolution. For instance, barricades shielded the protestors from the viciousness of the police and the regime's militia-especially the outer barricades. Moreover, they have played an offensive role by providing the protestors with the time and opportunity to elucidate their cause to the regime soldiers and some of the reluctant citizens that were not involved in the movement at the beginning [23]. From the management perspective, the barricades acted as a crowd management tool, as a messaging platform, and as a gathering point.

The sit-in space's outer barricades were solidly built and massively guarded and controlled by the protestors. In contrast, the inner barricades were beautifully colored and painted. The inner barricades represented the transitional zone between the high-tension area marked by the sit-in space's outer barricades and the internal, active public space set by the protestors. The protestors further expressed this duality of spaces as "the minute you walk through the inner barricades, you tend to forget all police forces and the security personnel surrounding and shooting the protestors at the outer barricades". [23]. The symbolic function of the barricades was rather intricate, as protestors utilized them to represent a symbol of the pride and endurance of their movement and the sit-in occupation. Figure 13 also shows that the inner barricades of the sit-in space became a symbol of achievement and optimism, a meeting point, and a public art zone.

The northern barricades have unceasingly become spaces for encounter, contestation, and dialogue between the Army and the Rapid Support Forces (RSF), from one side, and protestors, from the other. One of the northern barricade guardians mentioned that "we are the barricade, not those stones" [39]. This statement demonstrates that protestors were in continuous debates over the revolution at the barricades with the Army and police force. Such behavior was observed clearly after the Transitional Military Council (TMC) took power and arrested al-Bashir. Additionally, the barricades also transformed the sit-in space into an authentic walkable promenade favored with excellent accessibility. The barricades also transformed many surrounding places and streets into walkable entry points to the sit-in-among which the famous Blue Nile bridge. 


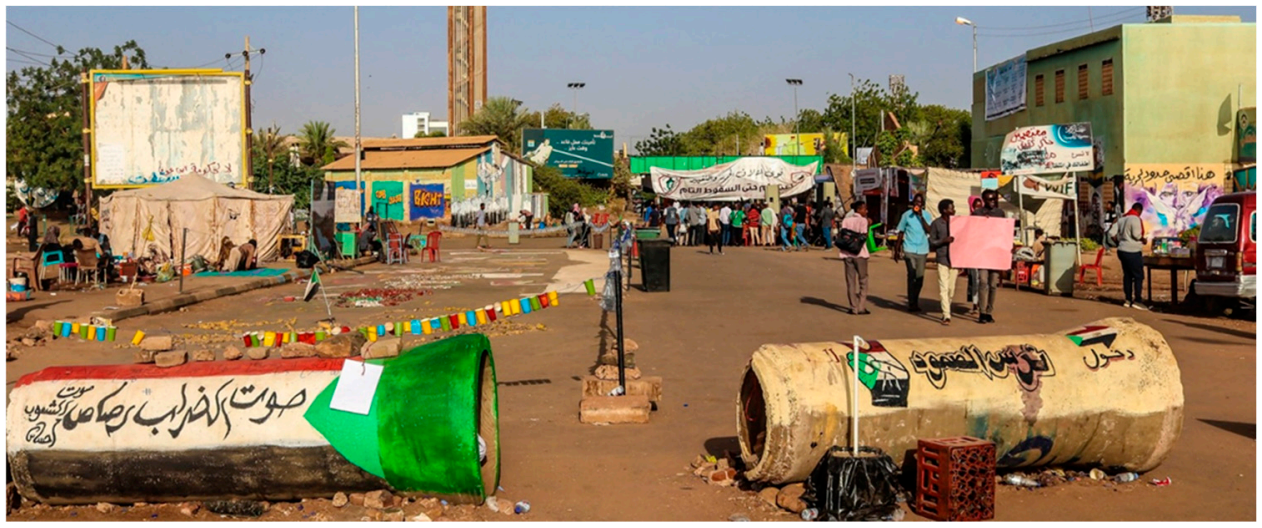

Figure 13. The photo shows the "al-Simoud" barricade, on the northern side of the sit-in. Note the public street art behind the barricade.

\subsection{Public Arts, Graffiti, and Culture in the Sit-In}

The third crucial spatial construct is the public art, graffiti, and culture produced and consumed during the sit-in period. The use of public artworks, graffiti, and culture as a tool of protest is not a new practice, as seen in Tahrir Square, in Egypt [40], and Taksim Square, in Istanbul [41]. However, the sit-in space provided the opportunity for many artists to freely express their views and ideas in what artists considered as the most significant art and graffiti workshop and cultural exchange hub in Sudan's history [23].

During the days of the revolution, protestors utilized street art to tease al-Bashir's regime and to express citizen demands for change (Figure 14). Graffiti, sculptures, murals, reliefs, and art objects have all participated in transforming the character of the sit-in space and other parts of the city into a fortress of beauty and political messages. However, it is important to note that public art in the sit-in space was not represented only by the above-mentioned elements. Other innovative features, including an open-air museum exhibiting the loots that protestors claimed from regime soldiers during the revolution, were unique forms of public art shown in the sit-in. Some protesters considered the cultural diversity and the gathering process in the sit-in space as art, which they described as "involving people from all over the country; the sit-in space was a gigantic social and cultural graffiti" [42].
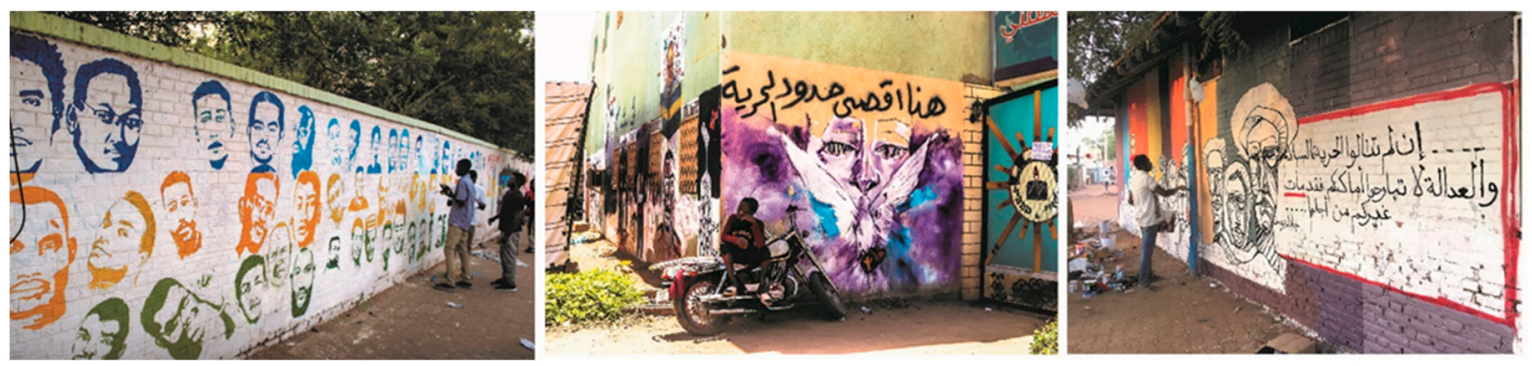

Figure 14. Three images that show the art and the graffiti exhibited in the sit-in space. On the left, graffiti fills a mural commemorating the martyrs of the Nile spring. The central photo shows a dove mural, expressing the success of the sit-in. On the right, a message that urges protestors not to leave their sit-in space until liberty, peace, and justice are achieved. The central image was provided by Ali Gaffar.

From a cultural perspective, protestors from more than nine Sudanese cities established their encampments in front of al-Qeyada. Those encampments were rapidly transformed from a symbol of revolution support into a cultural exchange hub. Protestors started to exhibit their regional culture and traditions through performances, dance, food, drinks, dress, and music. The main performance stage played a significant role in exhibiting this cultural diversity (Figure 15). More than 26 cultural 
shows, including singing, dancing, music, and theater, were presented in the main sit-in stage during the month of Ramadan [23]. This number does not include the cultural activities around the other sit-in spaces.

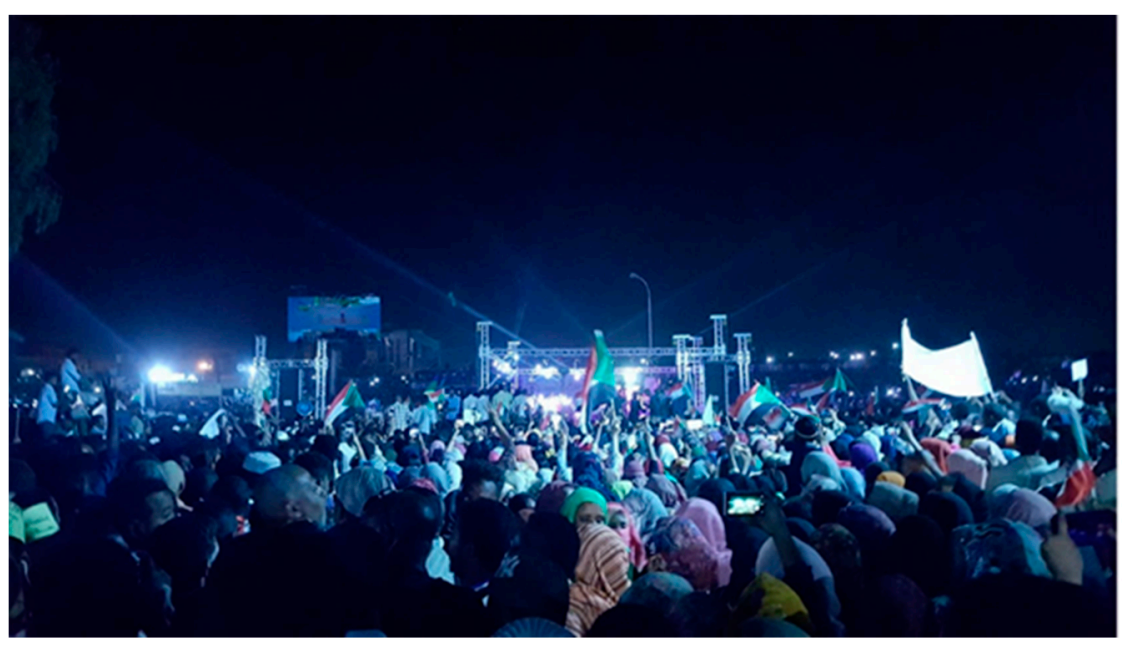

Figure 15. The public stage during a night event,. Photo courtesy of Ali Gaffar.

In addition to the three constructs mentioned above, the sit-in was also a hallmark of solidarity and charity. Protestors funded many of the activities discussed above through self-help. Donation boxes were set-up across the sit-in to collect money for those in need. Protestors used carpooling for transportation, shared transport costs, and provided free water and meals for those who could not afford them. The sit-in pharmacy provided free medication not only to protestors but also to Khartoum residents at large. Many of the scarce medicines that were not available in local pharmacies might be found for free in the sit-in pharmacy [43]. Besides, most of the supplies for art workshops, medical check-ups, and banner printing were all subsidized by the protestors [43].

\section{Discussion}

Democratic Public Spaces are necessary to safeguard socio-cultural reforms [11,44], to share knowledge [45], information [11], and perceptions that are indispensable to the construction of all-encompassing public social policy. The role of the streets and open spaces during the actions of the revolution showed that authentic public spaces within a city are fundamental. After the occupation of the sit-in space, its functionality was redefined by both the protestors and the process, that managed to reclaim both the space and social democracy. As the sit-in gradually transformed into a space of interventions, debates, public arts, and culture, it managed to attract various social, economic, and religious perspectives.

The sit-in fosters a civic engagement through which the occupation, creation, and appropriation of public spaces becomes a participatory workshop that involves almost everyone. Hence, the sit-in seems to have provided a new vision for the relationship between urban design, urban space, and politics. This vision is based on the departure from a political system that creates architecture and spaces to express its power, i.e., al-Saha Al-khadra (the Green Yard), the Army headquarters, the National Intelligence Club, toward an urban design and urban spaces that harvest and reconstruct the country's fragile political and socio-cultural system. The activities of the sit-in (Figure 7) involved various members of society, including youth, women, elders, religious groups, and professional associations. It also involved different social and economic classes as well as citizens that assembled from more than nine Sudanese cities [37]. This gathering showed not only the diversity of the protestors in the sit-in but also how the socio-cultural differences — that had previously fueled the civil war in Sudan [46] — could rebuild society starting from the sit-in space. The collective action that appropriated the sit-in reflected Harvey's argument that the right to the city " ... is not merely a right of access to what exists, but a 
right to change it after our heart's desire" [47] (p. 236). In addition, the sit-in collective occupation and transformation has satisfied Harvey's [16] perception of the role of urban revolution as an endeavor to transform public space into a political common; this common must be collective and non-commodified, similar to a Habermasian public sphere [30].

The regime's control over the public sphere and public space may have changed the domain through which protestors retrieved their right to the city. Demonstrators often called the sit-in space the "liberated land of the republic of al-Qeyada", to distinguish the sit-in space from other public areas in Khartoum. Such a name indirectly recognized other public spaces in Khartoum as "not free". The streets seem to have become, therefore, the only physical space that compensated such loss of public space. Hence, the act of reclaiming the public space in Khartoum cannot be seen or understood without the December uprising. It was perhaps not a battle over spaces but a quest to prioritize the public's demands over the regime's interests in a way that merged the public realm with the public sphere and the public domain. The events that followed the occupation of the sit-in space progressively transformed the space from an instrument of liberation into a workshop for creating a model for an alternative society [48]. During the sit-in, protestors turned al-Qeyada into an interactive convention of local traditions and international waves of ideas and thoughts that were channeled through the sit-in activities and spatial constructs to the protestors. These layers of interaction between local and international thoughts fueled ideas and information exchanges. Driven by the sensation of the value of the individual and the society, the sit-in gave birth to plentiful space meaning through instant graffiti, poetry, music, songs, and, most importantly, provided the space for democratic debates and cultural exchanges among various groups, classes, and ethnicities. This spatial condition is what Lefebvre [15] labeled as "the lived space", which he identified as a more potent space than the "perceived spaces". Lived space tends to interact with people's spatial experience and to create memories. In addition, the assortment mentioned above replicates the tripartite elements of the place attachment framework, as presented by Scannell \& Gifford [32]. In other words, the sit-in space demonstrated a strong bond between protestors and space.

The fifty-eight days of the sit-in managed to launch an inclusive democratic public space and activities that can be described as:

1. Democratic and free, equally accessible to everyone.

2. Meaningful, by incorporating notable amenities and features that connected users and their daily life.

3. Engaging, designed with an active use.

4. Responsive, in that they provided spaces for discovery, activities relations, learning, and debate.

5. Mediator of conflicts, as they allocates spaces to many conflicting ideologies and groups to meet and discuss their points of view.

The five values above were described in critical urban design studies as fundamental for authentic public space, i.e., Carmona [33], the Project for Public Space [34], and Kellett [49] (p. 97). At this point, on might ask why the sit-in space has gained this prominence and publicity while other public spaces in Khartoum simply failed. To answer this question, we need to revisit the urban design's theoretical framework, that deals with the quality of public space and space production. Both of Carmona's [33] rules of successful public space and the PPS's [34] qualities for successful public space have been observed in the sit-in space. The sit-in was full of street life, evening uses, activities, volunteerism-and, above all, it was inclusive. Children, women, elders, wealthy, poor, Muslims, Christians, Africans, and Arabs were all observed in the sit-in space, supporting the sit-in different activities. Furthermore, the sit-in was safe, walkable, sittable, and attractive. Those four elements confidently respond to the aspects of place comfort, place accessibility, and place sociability as identified by the PPS [34].

The two examples presented above stressed the importance of the user experience and the attachment to the public space. The connection between people and their emotional environments-often called "place attachment"-is central to both Carmona [33] and PPS [34]. 
In this regard, the sit-in space has generated a positive attachment between people and an area that was previously only a couple of parallel streets. Most of Carmona's [33] rules of successful public space as well as all the PPS's [34] principles were present at the sit-in space. In addition, the functions and activities demonstrated during the sit-in were unmatched in the modern history of Sudan's public space. The sit-in did foster an urban sense of space, as defined by Montgomery [50]; this was supported by the 27.5 hectares of a walkable sit-in, the spectrum of activities, and the spatial constructs exhibited in Figures 4 and 7. In other words, the activities observed in the sit-in space reflect the vitality and the diversity of the space. The last two concepts are considered the main components of the auspicious activity [50].

Finally, Building on Jürgen Habermas's theories on the role of the public sphere in democratic discourses [30], and the variety of activities exhibited in the sit-in, the occupied space has represented what Hauser [51] called a "discursive space" and defined as a "... space in which individuals and groups congregate to discuss matters of mutual interest and, where possible, to reach a common judgment" [51] (p. 86). This testimony indicates that the sit-in space reflected both the public sphere and the public domain of the protestors.

\section{Conclusions}

This research has shown the role of activities and public discourses in a revolutionary context. The article recognized the positive role of the sit-in activities and spatial constructs both as a mechanism of space democratization and a tool of social and cultural change. The activities of the sit-in space have brought the notion of a vibrant public space to the forefront of discourses on contemporary urbanism in Khartoum, as it restored the faith in public space as an instrument of change. Besides, the manifestation of those activities in a temporal space such as the sit-in, triggered a broader array of social possibilities as well as a new culture of social accountability and engagement through the protestors' participation in different activities.

Moreover, the sit-in activities facilitated a sort of dialogue between the spaces of tradition and modernity among activities that are unlikely to spatially co-exist [52]. This allows us to qualify the activities of the sit-in as both "creative" and "generative". The activities were "creative" in that they managed to provide a set of diverse social, political, cultural, economic, and artistic activities that rarely co-existed in Khartoum before the revolution. They were also "generative" in that they produced a new culture of acceptance and marriage between modernity and tradition, between local and global, between different religious and cultural groups, and between various social classes. The introduction of uncensored political activities into the public space in Khartoum, as observed in the sit-in, is also a "generative" construct of shared visions and an emerging urban phenomenon.

The sit-in space in front of al-Qeyada is perhaps the most identifiable spatial icon associated with Sudan's third revolution—so much so that many observers have labeled the Nile Spring as the Midan al-Qeyada revolution. The al-Qeyada sit-in demonstrated that public spaces are not just vacuums or empty lands, as the majority of public spaces in Khartoum during the al-Bashir regime; instead, they are an accumulation of social, cultural, and political forces of the city, blended in a way that restores the pride and the right to public spaces. Today, it is no longer surprising to see many "non-spaces" and empty walls bombarded with socio-cultural and political activities as well as beautiful graffiti, powerfully illustrating this transformation.

Three key lessons can be learned from the spatial experience and the democratic practice and activities in the sit-in space. First and foremost, the activities of the sit-in fostered a model of place-making that showcased remarkable structures of social coherence, cultural marriage, public engagement, shared vision, and, most importantly, collective action to design, appropriate, and manage public space. The sit-in space occupation demonstrated that, regardless of the level of control and power exhibited, the public space can still become "insurgent", as described by Hou [7] or "loose", as mentioned by Franck \& Stevens [53]. Either way, a genuine public space-like the sit-in space in al-Qeyada—is a potent tool in the struggle over public space. 
Secondly, while the triumph of the December 2018 revolution remains much contested, it is evident that the sit-in has challenged the very conception of the relationship between public space and political ideology through the provision of a new practical example of what a public space is. Through the utilization of activities and spatial constructs as agents of change, the sit-in succeeded in revolutionizing the understanding of what is public and how public spaces should be imagined, designed, and managed. The process of occupying the sit-in space has generated "a new meaning" for both the revolution and the space it occupied. For the first time in Sudan history, a genuine public space was produced, appropriated, and transformed in a way that contested local systems of public space production.

Finally, the al-Qeyada sit-in space disclosed the necessity to rethink current planning and urban design procedures of urban spaces and the city at large that failed to provide spaces for political and socio-cultural transformations. Such transformation can be achieved through two main formulas: democratizing access to space and democratizing the ability to produce places. Nevertheless, it is noteworthy that none of these two recipes can be realized without democratizing the state itself.

This article has reflected on Khartoum's sit-in space during the December uprising, exploring the public discourses, activities, and the space transformation during the sit-in period. However, the case of Sudan's uprising and its unfolding events raises a theoretical dilemma on the process of generating, appropriating, and managing public space, which will continue to dominate research and pragmatic domains for some time. The results exhibited above emphasize the role of the sit-in space and its transformation; therefore, they cannot be considered as having produced a paradigm shift in the mechanism of public space production. Nevertheless, it is crucial to question whether the sit-in space was a genuine declaration of the public rejection of public space design and planning policies, or just the result of a political exercise against a corrupt regime. Is there now a need for alternative strategies that can replicate what has happened in the al-Qeyada sit-in? How to sustain this rebirth of the image and character of the sit-in space to transform the socio-spatial configuration of Khartoum and create vibrant community spaces that exploit the sit-in's political, social, economic, and cultural significance? What kind of interventions are required to support this social change? How to put these interventions into practice in terms of planning and policy framework? Or should the public, in Khartoum and Sudan at large, redefine their relationship to public space at the current historical juncture?

Funding: This research was funded by the Deanship of Scientific Research (DSR), King Abdulaziz University, Jeddah, under grant no. (DF-775-137-1441). The author, therefore, gratefully acknowledges the DSR's technical and financial support.

Conflicts of Interest: The author declares no conflict of interest.

\section{References}

1. Madanipour, A. Temporary use of space: Urban processes between flexibility, opportunity and precarity. Urban Stud. 2018, 55, 1093-1110. [CrossRef]

2. Parkinson, J. Democracy and Public Space: The Physical Sites of Democratic Performance; Oxford University Press: Oxford, UK, 2012.

3. Sassen, S. To Occupy. In Beyond Zuccotti Park: Freedom of Assembly and the Occupation of Public Space, 1st ed.; Shiffman, R., Bell, R., Brown, L.J., Elizabeth, L., Fisyak, A., Venkataraman, A., Eds.; New Village Press: New York, NY, USA, 2012; pp. 67-73.

4. Bahreldin, I.Z. Rethinking Contemporary Public Spaces in Khartoum; the sit-in space invention and appropriation in Sudan's December Revolution 2018. In Proceedings of the International Seminar: "Public Space, Public Sphere, and Publicness in the Middle East", Cairo, Egypt, 8-9 March 2020.

5. Mitchell, W.J. Image, space, revolution: The arts of occupation. Crit. Inq. 2012, 39, 8-32. [CrossRef]

6. Stephenson, K. From Tiananmen to Tahrir. Knowing one's place in the 21st century. Organ. Dyn. 2011, 40, 281-291. [CrossRef]

7. Hou, J. (Not) your everyday public space. In Insurgent Public Space: Guerrilla Urbanism and the Remaking of Contemporary Cities, 1st ed.; Hou, J., Ed.; Routledge: New York, NY, USA, 2010; pp. 1-18. 
8. Alraouf, A.A. Creative Urban Chaos in Cairo's Spaces after the January 2011 Revolution; the Nile Bridges and Maidan Tahrir. Omran 2011, 5, 33-62.

9. Rabbat, N. The Arab Revolution Takes Back the Public Space. Crit. Inq. 2012, 39, 198-208. [CrossRef]

10. Goes, E. Power and the public sphere: Lessons from Tahrir square. Port. J. Soc. Sci. 2015, 14, 57-70. [CrossRef]

11. Zhang, J.; Nyíri, P. “Walled” activism: Transnational social movements and the politics of Chinese cyber-public space. Int. Deve. Plan. Rev. 2014, 36, 111-132. [CrossRef]

12. Carmona, M. The Place-shaping Continuum: A Theory of Urban Design Process. J. Urban Des. 2014, 19, 2-36. [CrossRef]

13. Salama, H.H. Tahrir square a narrative of a public space. Archnet-IJAR 2013, 7, 128-138.

14. Hou, J. Making Public, Beyond Public Space. In Beyond Zuccotti Park; Shiffman, R., Bell, R., Brown, L.J., Elizabeth, L., Fisyak, A., Venkataraman, A., Eds.; New Village Press: Oakland, CA, USA, 2018; pp. 89-98.

15. Lefebvre, H. The Production of Space; Nicholson-Smith, D., Ed.; Basil Blackwell: Oxford, UK, 1991.

16. Harvey, D. Rebel Cities: From the Right to the City to the Urban Revolution; Verso: London, UK, 2012.

17. McLaren, D.; Agyeman, J. Sharing Cities: Governing the City as Commons. In The City as Commons: A Policy Reader; Ramos, J.M., Ed.; Commons Transition Coalition: Melbourne, Australia, 2016; pp. 77-79.

18. Low, S.; Iveson, K. Propositions for more just urban public spaces. City 2016, 20, 10-31. [CrossRef]

19. Iveson, K. Cities within the City: Do-It-Yourself Urbanism and the Right to the City. Int. J. Urban Reg. Res. 2013, 37, 941-956. [CrossRef]

20. Wright, T. New urban spaces and cultural representations: Social imaginaries, social-physical space, and homelessness. In Constructions of Urban Space; Hutchison, R., Ed.; Emerald Publishing: Bingley, UK, 2015; pp. 23-57.

21. Deshayes, C. Reclaiming the streets: Strategies of re-appropriation of a political public sphere in Sudan. In Proceedings of the International Seminar: "Public space, public sphere, and publicness in the Middle East", Cairo, Egypt, 8-9 March 2020.

22. Hassan, S.; (University of Khartoum, Khartoum, Sudan). Personal communication, 26 May 2019.

23. Khalid, A.; (al-Neelain University, Khartoum, Sudan). Personal communication, 14 April 2019.

24. Bahreldin, I.Z. Public Space Invasion and Vandalism in Khartoum; al-Zaem al-Azhari Univerity: Khartoum, Sudan, 2005.

25. Ahmad, A.M. Khartoum Blues: The 'Deplaning' and Decline of a Capital City. Habitat Int. 2000, 24, 309-325. [CrossRef]

26. Hamid, M. Rethinking the Open Spaces of Khartoum's Residential Fabric. In Proceedings of the Architects 4th Scientific and Professional Conference, Khartoum, Sudan, 8-9 May 2016.

27. Al-Karib, H. Interview with Washington Post. Available online: https://www.reuters.com/article/us-sudanwomen-protests/its-about-freedom-women-on-the-frontline-of-sudans-uprising-idUSKCN1PV1U2 (accessed on 9 September 2019).

28. Lefebvre, H. The Urban Revolution; Bononno, R., Ed.; University of Minnesota Press: Minneapolis, MN, USA, 2003.

29. Purcell, M. The right to the city: The struggle for democracy in the urban public realm. Policy Polit. 2013, 42, 311-327. [CrossRef]

30. Habermas, J. Further Reflections on the Public Sphere; Calhoun, C., Ed.; MIT Press: Cambridge, UK, 1992; pp. 421-461.

31. Gottdiener, M.; Hutchison, R. The New Urban Sociology, 4th ed.; Westview Press: Boulder, CO, USA, 2011.

32. Scannell, L.; Gifford, R. Defining Place Attachment: A Tripartite Organizing Framework. J. Environ. Psychol. 2010, 30, 1-10. [CrossRef]

33. Carmona, M. Principles for public space design, planning to do better. Urban Des. Int. 2019, 24, 47-59. [CrossRef]

34. Project for Public Spaces, What Is Placemaking? Available online: https://www.pps.org/article/you-askedwe-answered-6-examples-of-what-makes-a-great-public-space (accessed on 24 August 2019).

35. Florek, M. No place like home: Perspectives on place attachment and impacts on city management. J. Town City Manag. 2011, 1, 346-354. 
36. Beyond Trousers: Public Order Laws and Women's and Girls' Rights in Sudan; A Discussion Paper Submission to the 46th Ordinary Session of the African Horn Women Strategic Initiative (SIHA): Banjul, Gambia, 12 November 2009; Available online: http://www.wluml.org/sites/wluml.org/files/Beyondtrousesarabic.pdf (accessed on 13 September 2019).

37. Ammar, A.; (Journalist \& Protestor, Sudan Twitter Forum, Khartoum, Sudan). Personal communication, 26 May 2019.

38. Saeed, T.; (University of Khartoum, Khartoum, Sudan). Telephone interview. Personal communication, 12 September 2019.

39. Hassan, M.; (Barricade Guardian, Protestor). Personal communication, 23 June 2019.

40. Abaza, M. Post-January Revolution Cairo: Urban Wars and the Reshaping of Public Space. Theory Cult. Soc. 2014, 31, 163-183. [CrossRef]

41. Baykan, A.; Hatuka, T. Politics and culture in the making of public space: Taksim Square. Plan. Perspect. 2010, 25, 49-68. [CrossRef]

42. Hammad, K.; (Protestor). Personal communication, 16 June 2019.

43. Abdellah, R.; (Federation of Sudanese Pharmacists, Protestor). Personal communication, 17 May 2019.

44. Iveson, K. Social or spatial justice? Marcuse and Soja on the right to the city. City 2011, 15, 250-259. [CrossRef]

45. Said, A. We ought to be here: Historicizing space and mobilization in Tahrir Square. Int. Soc. 2015, 30, 348-366. [CrossRef]

46. Khalid, M. War and Peace in the Sudan, 1st ed.; Kegan Pau: London, UK, 2002.

47. Harvey, D. The New Imperialism; Oxford University Press: Oxford, UK, 2003.

48. Adil, K.; (Journalist). Personal communication, 9 June 2019.

49. Kellett, P. Constructing Informal Place. In Constructing Place: Mind and Matter; Menin, S., Ed.; Routledge: London, UK, 2003; pp. 87-98.

50. Montgomery, J. Making a city: Urbanity, vitality, and urban design. J. Urban Des. 1998, 3, 93-116. [CrossRef]

51. Hauser, G.A. Vernacular dialogue and the rhetorically of public opinion. Commun. Monogr. 1998, 65, 83-107. [CrossRef]

52. Kamal, H.; (Journalist). Telephone interview. Personal communication, 23 August 2019.

53. Franck, K.A.; Stevens, Q. Tying down loose space. In Loose Space: Possibility and Diversity in Urban Life, 1st ed.; Routledge: Abingdon, UK, 2007.

(C) 2020 by the author. Licensee MDPI, Basel, Switzerland. This article is an open access article distributed under the terms and conditions of the Creative Commons Attribution (CC BY) license (http://creativecommons.org/licenses/by/4.0/). 